\title{
Foundations
}

\section{Etiology and Anatomic Distribution of Venous Disease in Patients with Venous Ulcers}

\author{
NICOS LABROPOULOS, Ph.D., D.I.C., R.V.T., and \\ APOSTOLOS K. TASSIOPOULOS, M.D.
}

\begin{abstract}
Leg ulcers due to chronic venous disease affect 0.5 to $1 \%$ of Western populations. Reflux and/or obstruction of the lower extremity veins are the underlying pathophysiological mechanisms. The superficial venous system is the most common site of venous insufficiency in patients with chronic venous disease; however, the incidence of deep venous insufficiency is increased in patients with venous ulcers. Skin damage is most often associated with multisystem incompetence, and it is rare with deep venous reflux alone. Only 30 to $\mathbf{5 0 \%}$ of limbs with ulceration have a documented episode of deep vein thrombosis. Recent developments in the diagnosis of venous disease have allowed more accurate identification of the malfunctioning venous segments and a more rational application of surgical treatment.
\end{abstract}

Keywords Chronic venous disease, deep vein thrombosis, ambulatory venous pressure

Lower extremity ulceration represents the most advanced stage of chronic venous disease (CVD). Venous hypertension secondary to venous outflow obstruction, reflux, or both is the main cause for it.

For many years, the study of CVD suffered from the lack of a sufficiently organized classification system, which made comparison between reports and treatment results difficult. Moreover, different investigators used a variety of diagnostic procedures, invasive and noninvasive, to study the distribution and

\footnotetext{
N.L., Assistant Professor of Surgery; A.K.T., Vascular Fellow; Department of Surgery, Loyola University Vascular Center, Maywood, IL.

Copyright (C) 2000 by Thieme Medical Publishers, Inc., 333 Seventh Avenue, New York, NY 10001, USA. Tel. $+1(212)$ 584-4662. 0894-8046,p; 2000,12,2,117,126,ftx,en;pvs00072
} 
pathophysiology of venous disease. The lack of standardized techniques in these procedures further added to the confusion. Duplex ultrasound examination of the lower extremity veins was introduced in recent years and significantly improved our understanding of the etiology of CVD. This noninvasive test allowed a more accurate identification of the malfunctioning vein segments and has shown that reflux is the predominant cause of ulceration with a significant contribution of the superficial system. These observations contributed to the development of a more rational therapeutic approach.

In 1994, an international committee on $\mathrm{CVD}^{1}$ revised the previously existing classification system and suggested that limbs with CVD should be classified according to clinical signs (C), etiology (E), anatomic distribution (A), and pathophysiological condition (P). This system (CEAP) was designed to provide the additional details necessary to accurately compare limbs in treatment trials.

\section{CLINICAL PRESENTATION OF CVD}

Seven clinical classes (0-6) were described in the CEAP classification. Limbs in higher categories have more severe signs of CVD and may have some or all of the findings defining a less severe clinical category. Each limb is further characterized as symptomatic (S) or asymptomatic (A). ${ }^{1}$ The most common symptoms seen with telangiectases and reticular and varicose veins include lower extremity aching, pain, skin irritation, itching, heaviness, and burning sensation.

The prevalence of lower extremity ulceration secondary to CVD in European and Western populations is estimated to be 0.5 to $1 \%{ }^{2,3}$ In a cross-sectional population study of 382 patients with active leg ulcers, Nelzen et al. ${ }^{4}$ reported that venous insufficiency was the dominating etiologic factor in $54 \%$, and the overall incidence of venous disease in this selected population was $72 \%$. This percentage is significantly different from previous reports in the middle of the 20th century that quoted venous etiology in 84 to $97 \%$ of patients with leg ulcers. ${ }^{5-7}$ It is very likely that the prevalence of CVD as a cause of ulceration has been underestimated in this study ${ }^{4}$ for the following reasons. Only four sites of the leg veins were examined for reflux and obstruction, using a bidirectional Doppler. It has been shown, however, that saphenous reflux can exist in the absence of saphenofemoral or saphenopopliteal incompetence. ${ }^{8,9}$ Also, arterial disease was defined as an ankle to brachial index $(\mathrm{ABI})$ of $<0.9$ without necessarily this being the cause of the ulcer because many of the limbs had an ABI of $>0.5$. Similar results have been reported in other studies that suggest a change in the etiologic spectrum toward arterial and mixed ulcers most likely due to the ongoing aging of the population. ${ }^{10,11}$ However, the following limitations exist in these studies. Clinical examination was used to evaluate CVD in one study, ${ }^{11}$ whereas in the other, ${ }^{10}$ the sample size was small and patients with foot ulcers only were excluded. 


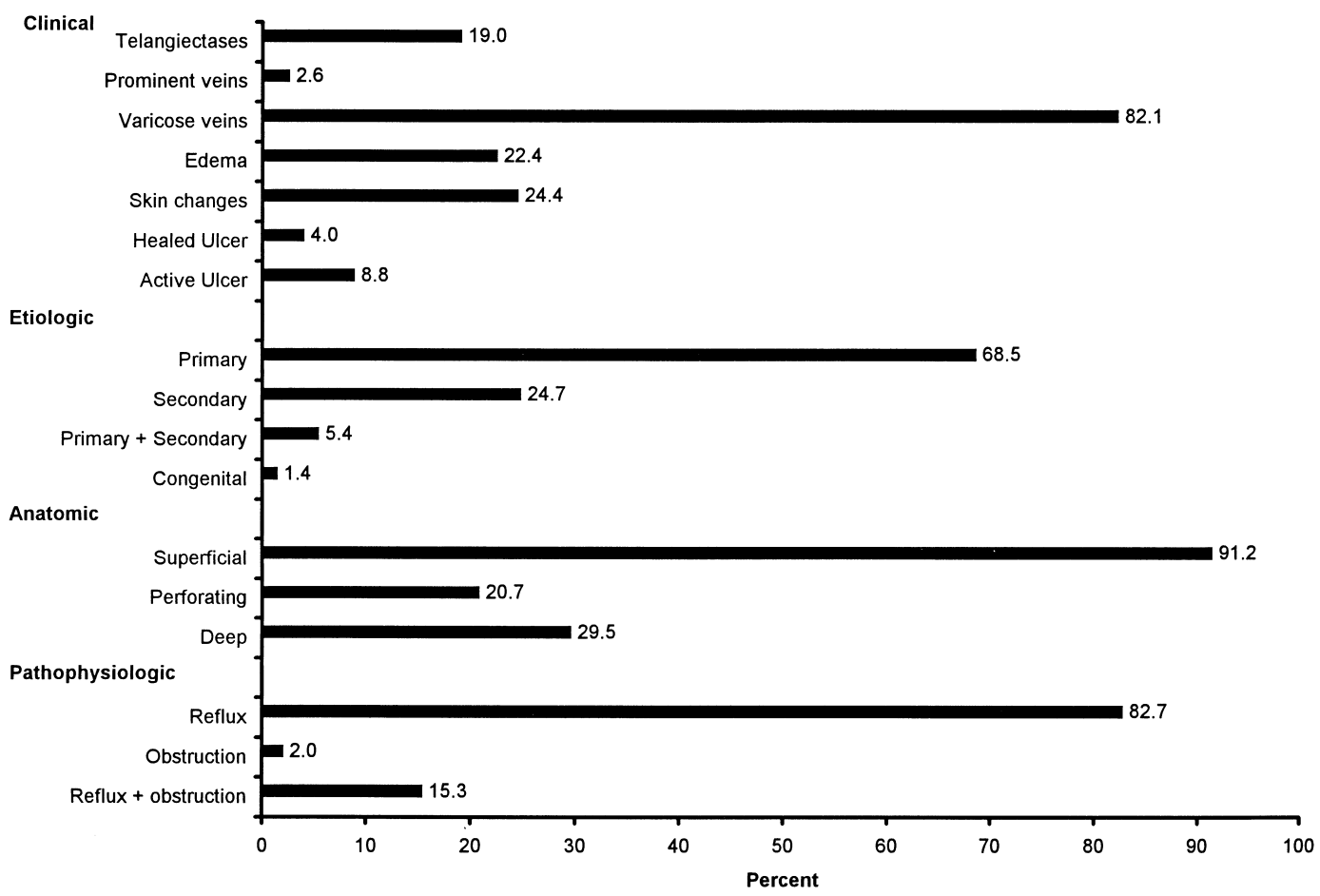

Fig. 1 Combined data from the two main studies using the CEAP classification system on consecutive patients. ${ }^{12,13}$

Kistner et al. ${ }^{12}$ applied the CEAP classification in 102 legs of 70 patients with CVD. They found 14 legs $(13.7 \%)$ with ulceration $\left(\mathrm{C}_{5-6}\right)$. In a similar study of 250 limbs in 182 patients, Labropoulos ${ }^{13}$ reported that $5.2 \%$ had healed ulcers $\left(\mathrm{C}_{5}\right)$ and $7.2 \%$ had active ulcers $\left(\mathrm{C}_{6}\right)$. The combined results of these studies are presented in Figure 1.

\section{ETIOLOGY}

According to CEAP classification the etiology of CVD may be congenital $(\mathrm{C})$, primary $(\mathrm{P})$, or secondary $(\mathrm{S}) .^{1}$

Congenital anomalies of the lower extremity veins are responsible for a very small number of leg ulcers and are rarely diagnosed. These abnormalities are present at birth but may be recognized later. Primary venous dysfunction denotes CVD of undetermined etiology. CVD may also be secondary to an acquired condition such as deep vein thrombosis (DVT) or trauma.

In the study mentioned above, Labropoulos ${ }^{13}$ reported that $0.8 \%$ of the limbs had congenital abnormalities, $64 \%$ had primary CVD, and $27.6 \%$ secondary. In $7.6 \%$ primary venous insufficiency existed in some vein segments 
and secondary in others. These were usually patients with previously diagnosed varicose veins who developed DVT and subsequent deep venous reflux during their follow up period. The same author studied 94 patients with 112 ulcerated limbs and found that $39 \%$ of the affected limbs had DVT and 3\% had superficial thrombophlebitis in the past. ${ }^{14}$ Kistner et al. ${ }^{12}$ reported congenital etiology in 3\% of the limbs, primary in 79\%, and secondary in $18 \%$ (all postthrombotic). No patients with both primary and secondary CVD were reported in this study. Venous ulcers were found in 8 of 18 limbs (44\%) with secondary CVD ( 7 were $\mathrm{C}_{6}$ and 1 was $\mathrm{C}_{5}$ ). Of the remaining 10 limbs, 7 were $\mathrm{C}_{4}$ and 3 were $\mathrm{C}_{3}$. Only $7 \%$ of limbs with primary CVD had ulcers. Other reports ${ }^{15-19}$ also show that in limbs with ulcers the incidence of previous DVT is higher compared with limbs with clinically less severe CVD. These data clearly suggest that primary disease is significantly more common than secondary, but patients with secondary disease develop more advanced clinical signs.

\section{ANATOMIC DISTRIBUTION}

Based on the anatomic classification in CEAP, the vessels involved should be described as superficial, deep, or perforating. ${ }^{1}$ Any combination of these systems may be affected. The studies by Kistner et al. ${ }^{12}$ and Labropoulos ${ }^{13}$ show that the superficial veins are affected in $90 \%$ of limbs with CVD, the deep venous system only in $30 \%$, and the perforator veins in $20 \%$ (Fig. 1). Of the 14 limbs with ulcers in the first study, ${ }^{12} 4$ had reflux limited to the superficial and perforator veins, 2 to the superficial and deep veins, 1 to the deep veins only, and in the remaining 7 all 3 venous systems had reflux.

For many years it was a common belief that venous ulcers resulted from reflux and/or obstruction of the deep venous system secondary to an episode of DVT. The introduction of color flow duplex scanning in the last decade has allowed a more detailed study of the anatomic distribution and pathophysiology of venous incompetence. Several recent studies $4,8,12,14,15,19-21$ have shown that reflux confined to the superficial veins alone is responsible for 17 to $54 \%$ of venous ulcers. Overall, reflux in the superficial veins is seen in 79 to $93 \%$ of limbs with ulceration. ${ }^{12,14,15,19,22,23}$

The prevalence of isolated deep vein reflux in ulcerated limbs ranges between 2.1 and $15 \% .8,12,19,23$ It should be noted however that, in the study that showed high prevalence, ${ }^{8}$ the perforating veins were not examined; therefore, this percentage was clearly overestimated. In both studies that used CEAP classification ${ }^{12,13}$ isolated deep venous reflux was seen in $6 \%$ of limbs, whereas overall involvement of the deep venous system is found in 29 to $50 \% .12,13,22,23$ The prevalence of deep venous reflux in patients with venous ulcers $\left(\mathrm{C}_{6}\right)$ is higher, ranging between 50 and 70\% in various reports. $12,14,15,19,24$

The hemodynamic significance of incompetent perforating veins remains a controversial issue. Some investigators reported that incompetent perforators 
do not contribute to venous hypertension, ${ }^{25-27}$ whereas others suggest that they are important. ${ }^{19,22,28-30}$ In most studies, reflux in the perforator veins only was seen in less than $3 \%$ of limbs with CVD. ${ }^{12-15,21}$ Although the role of these veins in the development of signs and symptoms remains unclear, their number and size increases with worsening of CVD. 19,31-34

Most patients with ulcers (52-70\%) have incompetence in more than one system, ${ }^{14,15,19,21}$ and reflux in all three venous systems is seen in 16 to $50 \%{ }^{12,14,15,19,21,23}$ Interestingly, in a small percentage (4-6.3\%) of limbs with apparent venous ulcers, no incompetence or obstruction is detected in any of the venous systems. ${ }^{14,19}$

In a study of 34 limbs with 43 ulcers, ${ }^{15}$ examination of the local veins (veins passing through the ulcer or within $2 \mathrm{~cm}$ from its periphery) revealed reflux in $86 \%$ of ulcerated areas. When the pattern of reflux in the local veins (superficial vs deep) was compared with that of the axial veins, it was found to be similar in limbs that had reflux limited to either the superficial or the deep venous system (with or without associated perforator incompetence). This finding explains the very good results of surgical treatment targeting the affected venous system in patients with this type of axial vein reflux. Conversely, when reflux was seen in both the superficial and deep venous systems, the pattern of reflux in the local veins was not predictable, indicating that examination of the local veins in the ulcer area may be necessary prior to applying a treatment plan. Reflux in the perforating veins at the ulcerated area was seen in only $28 \%$ of ulcers. Perforator reflux at that level was always associated with superficial and/or deep vein incompetence.

Regarding the distribution of the disease, it should be mentioned that saphenous reflux often occurs in the absence of saphenofemoral and saphenopopliteal junction incompetence..$^{9,35,36}$ This may in part explain why recent studies have found that junction ligation without stripping results more often in residual/recurrent varicosities. ${ }^{37-39}$

\section{PATHOPHYSIOLOGY}

The main mechanisms responsible for the symptoms and signs of CVD according to CEAP are reflux, obstruction, or a combination of the two. ${ }^{1}$ In the two main reports of patients with CVD who were classified using the CEAP system, ${ }^{12,13}$ obstruction without reflux was seen only in $2 \%$ of limbs and reflux with obstruction in 12 to $17 \%$. Combined reflux and obstruction was more often seen in limbs belonging to classes $\mathrm{C}_{4}$ to $\mathrm{C}_{6} .{ }^{13}$ This is not surprising because a recent prospective study demonstrated that a combination of reflux and obstruction had worst prognosis for developing skin damage compared with reflux or obstruction alone (odds ratio $3.5,95 \%$ CI 1.4-8.6). ${ }^{40}$ In a study of patients with venous outflow obstruction, ${ }^{41}$ the incidence of limb ulceration was $10 \%$, whereas $40 \%$ of patients belonged to clinical classes $\mathrm{C}_{4}$ to $\mathrm{C}_{6}$. Their symptoms, however, cannot be attributed to 
venous outflow obstruction exclusively because in all these patients some degree of reflux was detected. The hemodynamic changes in the venous system were more significant with more proximal obstruction and poor collateralization.

The prevalence of DVT increases with worsening of CVD. ${ }^{24} \mathrm{~A}$ documented episode of DVT was found in 33 to $50 \%, 12,14-19,22$ of patients with ulceration, which is much higher prevalence than any other CVD class. ${ }^{24}$ This prevalence is probably underestimated because many thrombi remain undetected. Some of these thrombi may resolve without leaving any evidence of luminal damage other than reflux. In patients with DVT the determinants for clinical severity include the extent of reflux, presence of persistent popliteal obstruction, and rate of recanalization. ${ }^{42}$ It has been demonstrated that rethrombosis occurs in $24.6 \%(95 \% \mathrm{CI}, 19.6-29.7 \%)$ of patients at 5 years and in $30.3 \%$ (95\% CI, 23.6-37.0\%) at 8 years. 43 The development of ipsilateral recurrent DVT had a significant relation with the risk for postthrombotic symptoms (hazard ratio, 6.4; 95\% CI, 3.1-13.3). ${ }^{43}$

The pathophysiological mechanism responsible for venous ulceration is venous hypertension. It has been shown ${ }^{44,45}$ that venous hypertension leads to increased capillary permeability to fibrinogen and extravasation of red blood cells through widened intercellular gap junctions. This results in deposition of extracellular matrix around the capillaries that consists of fibrin, collagen types I and III, tenascin, laminin, and fibronectin. It has been suggested that this pericapillary cuffing acts as a diffusion barrier for oxygen and perhaps other nutrients, causing hypoxia of the overlying dermis, which, therefore, becomes very susceptible even to minor trauma. ${ }^{44}$ There are, however, no convincing data to support this hypothesis. ${ }^{46}$ In fact, Michel a few years later demonstrated in a theoretical model based on the Krogh-Erlang equation that it is very unlikely for the pericapillary cuffs to act as diffusion barriers to oxygen ${ }^{47}$ More recently it has been shown that the the microvascular changes in the skin of limbs with CVD are characterized by activated endothelium and inflammatory cells in the perivascular space. ${ }^{48}$ There is some evidence to support endothelial injury form leukocytes that are being attached to the cutaneous microvessels. It has been hypothesized that such a repeated injury over a long period may be responsible for the development of local skin damage. ${ }^{48}$

Nicolaides et al. 49 measured the ambulatory venous pressure (AVP) in patients with CVD and found that, when it was less than $30 \mathrm{mmHg}$, the incidence of leg ulceration is zero. This incidence increased linearly with AVP to reach $100 \%$ when the AVP was greater than $90 \mathrm{mmHg}$. Poor calf muscle pump function has also been associated with CVD severity..$^{50}$ Christopoulos et al. ${ }^{50}$ showed that patients with ulceration had worst ejection fraction compared with patients with varicose veins only. However, when patients were matched for age and duration of disease in another study, the amount of reflux was found to be most significant for the severity of CVD. ${ }^{23}$ 


\section{CONCLUSION}

For many years the management of lower extremity ulcers due to CVD was rather empirical because the pathophysiology and anatomic distribution of the disease were in many cases unclear. Duplex ultrasound has proved that the superficial venous system is involved in over $90 \%$ of ulcerated limbs $12,14,15$ and represents an easily accessible target for surgical intervention. When venous ulceration is due to superficial and perforator incompetence, surgical treatment may heal up to $90 \%$ of the ulcers with very good medium- to longterm results. ${ }^{51,52}$ According to recent studies about 30 to $50 \%$ of patients with ulcers belong to this category. $8,14,15,19,20$ However, very often more than one venous system is incompetent in patients with venous ulcers, and the contribution of each system in the clinical picture may be difficult to determine. When the deep veins are involved surgery of the superficial veins has worst results with very high recurrence rates at 5 years. ${ }^{52}$ The modified Linton procedure in patients with refractory ulcers and deep vein reflux had a $22 \%$ recurrence rate at 4 years. ${ }^{53}$ In patients with deep venous reflux and/or obstruction additional procedures that can improve the underlying abnormality may be required. Few studies have shown encouraging results in such patients. ${ }^{54-57}$ Most recently Gloviczki et al., from the North American Study Group on endoscopic subfascial perforator ligation found that correction of superficial and perforator vein reflux in the absence of deep venous obstruction predicted ulcer healing. ${ }^{29}$ Posththrombotic limbs had a higher recurrence rate compared with limbs with primary venous reflux at 2 years (46 vs $20 \%, p<0.05)$. Therefore, a detailed study of the affected extremity that will identify and provide functional information about all malfunctioning venous segments is of outmost importance when planning the treatment of these patients.

The CEAP classification system was created to offer guidelines for reporting venous disease to improve precision and allow for more accurate comparisons between different reports. Use of this classification provides organized, detailed information about the key elements of venous abnormalities in each patient and clarifies the interrelationships among the clinical manifestations, etiology, anatomic distribution, and pathophysiology of CVD. Therefore, it will facilitate the development of more uniform treatment plans in the different categories of disease, thus improving the outcome of this common problem.

\section{REFERENCES}

1. Porter JM, Moneta GL, International Consensus Committee on Chronic Venous Disease. Reporting standards in venous disease: An update. J Vasc Surg 1995;21:635-645

2. Cornwall JV, Lewis JD. Leg ulcer revisited. Br J Surg 1983;70:681

3. Callam MJ, Ruckley CV, Harper DR, Dale JJ. Chronic ulceration of the leg: Extent of the problem and provision of care. Br Med J 1985;290:1855-1856 
4. Nelzen O, Bergqvist D, Lindhagen A. Leg ulcer etiology-A cross sectional population study. J Vasc Surg 1991;14:557-564

5. Anning ST. Leg ulcers-The result of treatment. Angiology 1956;7:505-516

6. Birger I. The chronic stage of thrombosis in the lower extremities. Acta Chir Scand 1947;95(suppl 1129):29-110

7. Gilje O. Ulcus cruris in venous circulatory disturbances. Investigations of the etiology, pathogenesis and therapy of leg ulcers. Acta Derm Venerol (suppl 22):Thesis 1949;159-174

8. Shami SK, Sarin S, Cheatle TR, Scurr JH, Coleridge Smith PD. Venous ulcers and the superficial venous system. J Vasc Surg 1993;17:487-490

9. Labropoulos N, Giannoukas AD, Delis K, et al. Where does venous reflux start? J Vasc Surg 1997;26:736-742

10. Cornwall JV, Dor CJ, Lewis JD. Leg ulcers: Epidemiology and aetiology. Br J Surg 1986;73:693-696

11. Callam MJ, Harper DR, Dale JJ, Ruckley CV. Chronic ulcer of the leg; clinical history. BMJ 1987;294:929-931

12. Kistner RL, Eklof B, Masuda EM. Diagnosis of chronic venous disease of the lower extremities: The "CEAP" classification. Mayo Clin Proc 1996;71:338-345

13. Labropoulos N. CEAP in clinical practice. Vasc Surg 1997;31:224-225

14. Labropoulos N, Leon M, Geroulakos G, Volteas N, Chan P, Nicolaides AN. Venous hemodynamic abnormalities in patients with leg ulceration. Am J Surg 1995;169:572-574

15. Labropoulos N, Giannnoukas AD, Nicolaides AN, Ramaswami G, Leon M, Burke P. New insights into the pathophysiologic condition of venous ulceration with color-flow duplex imaging: Implications for treatment? J Vasc Surg 1995;22:45-50

16. Browse NL, Clemenson G, Lea Thomas M. Is the postphlebitic leg always postphlebitic? Relation between phlebographic appearances of deep-vein thrombosis and late sequelae. Br J Med 1980;281:1167-1170

17. Raju S, Fredericks R. Valve reconstruction procedures for nonobstructive venous insufficiency: Rationale, techniques, and results in 107 procedures with two- to eight-year follow-up. J Vasc Surg 1988;7:301-310

18. Train JS, Schanzer H, Peirce EC, Dan SJ, Mitty HA. Radiological evaluation of the chronic venous stasis syndrome. JAMA 1987;258:941-944

19. Hanrahan LM, Araki CT, Rodriguez AA, Kechejian GJ, LaMorte WW, Menzoian JO. Distribution of valvular incompetence in patients with venous stasis ulceration. J Vasc Surg 1991;3:805-812

20. Sethia KK, Darke SG. Long saphenous incompetence as a cause of venous ulceration. Br J Surg 1984;71:754-755

21. Yamaki T, Nozaki M, Sasaki K. Color duplex ultrasound in the assessment of primary venous leg ulceration. Dermatol Surg 1998;24:1124-1128

22. Labropoulos N, Delis K, Nicolaides AN, Leon M, Ramaswami G, Volteas N. The role of the distribution and anatomic extent of reflux in the development of signs and symptoms in chronic venous insufficiency. J Vasc Surg 1996;23:504-510

23. Labropoulos N, Giannnoukas AD, Nicolaides AN, Veller M, Leon M, Volteas N. The role of venous reflux and calf muscle pump function in nonthrombotic chronic venous insufficiency. Correlation with severity of signs and symptoms. Arch Surg 1996;131:403-406

24. Labropoulos N. Clinical correlation to various patterns of reflux. Vasc Surg 1997;31:242-248

25. Burnand KG, O'Donnell TF Jr, Thomas ML, Browse NL. The relative importance of incompetent communicating veins in the production of varicose veins and venous ulcers. Surgery 1977;82:9-14

26. Bjordal R. Flow and pressure studies in venous insufficiency. Acta Chir Scand Suppl 1988; 544:30-33 
27. Stacey MC, Burnand KG, Layer GT, Pattison M. Calf pump function in patients with healed venous ulcers is not improved by surgery to the communicating veins or by elastic stockings. Br J Surg 1988;75:436-439

28. Zukowski AJ, Nicolaides AN, Szendro G, et al. Haemodynamic significance of incompetent calf perforating veins. Br J Surg 1991;78:625-629

29. Gloviczki P, Bergan JJ, Rhodes JM, Canton LG, Harmsen S, Ilstrup DM. Mid-term results of endoscopic perforator vein interruption for chronic venous insufficiency: Lessons learned from the North American subfascial endoscopic perforator surgery registry. The North American Study Group. J Vasc Surg 1999;29:489-502

30. Pierik EG, van Urk H, Wittens CH. Efficacy of subfascial endoscopy in eradicating perforating veins of the lower leg and its relation with venous ulcer healing. J Vasc Surg 1997;26:255-259

31. Lees TA, Lambert D. Patterns of venous reflux in limbs with skin changes associated with chronic venous insufficiency. Br J Surg 1993;80:725-728

32. Pierik EG, Wittens $\mathrm{CH}$, van Urk H. Subfascial endoscopic ligation in the treatment of incompetent perforating veins. Eur J Vasc Endovasc Surg 1995;9:38-41

33. Cockett FB, Elgan-Jones DE. The ankle blow-out syndrome. Lancet 1953;1:17-23

34. Labropoulos N, Mansour MA, Kang SS, Gloviczki P, Baker WH. New insights into perforator vein incompetence. E J Vasc Endovasc Surg. In Press

35. Abu-Own A, Scurr JH, Coleridge Smith PD. Saphenous vein reflux without incompetence at the saphenofemoral junction. Br J Surg 1994;81:1452-1454

36. Labropoulos N, Leon M, Nicolaides AN, Giannnoukas AD, Volteas N, Chan P. Superficial venous insufficiency: Correlation of anatomic extent of reflux with clinical symptoms and signs. J Vasc Surg 1994;20:953-958

37. McMullin GM, Coleridge Smith PD, Scurr JH. Objective assessment of high ligation without stripping the long saphenous vein. Br J Surg 1991;78:1139-1142

38. Sarin S, Scurr JH, Coleridge Smith PD. Assessment of stripping the long saphenous vein in the treatment of primary varicose veins. Br J Surg 1992;79:889-893

39. Labropoulos N, Touloupakis E, Giannoukas AD, Leon M, Katsamouris A, Nicolaides AN. Recurrent varicose veins: Investigation of the pattern and extent of reflux with color flow duplex imaging. Surgery 1996;119:406-409

40. Johnson BF, Manzo RA, Bergelin RO, Strandness DE Jr. Relationship between changes in the deep venous system and the development of the postthrombotic syndrome after an acute episode of lower limb deep vein thrombosis: A one- to six-year follow-up. J Vasc Surg 1995;21:307-312

41. Labropoulos $\mathrm{N}$, Volteas $\mathrm{N}$, Leon $\mathrm{M}$, et al. The role of venous outflow obstruction in patients with chronic venous dysfunction. Arch Surg 1997;132:46-51

42. Meissner MH, Caps MT, Zierler BK, et al. Determinants of chronic venous disease after acute deep venous thrombosis. J Vasc Surg 1998;28:826-833

43. Prandoni P, Lensing AW, Cogo A, et al. The long-term clinical course of acute deep venous thrombosis. Ann Intern Med 1996;125:1-7

44. Browse NL, Burnard KG. The cause of venous ulceration. Lancet 1982;31:243-245

45. Pappas PJ, Durn WN, Hobson RW II. Pathology and cellular physiology of chronic venous insufficiency. In: Gloviczki P, Yao JST, eds. Handbook of Venous Disorders. Guidelines of the American Venous Forum. London: Chapman \& Hall; 1996:44-59

46. Moneta GL, Nehler MR. The lower extremity venous system: anatomy and physiology of normal venous function and chronic venous insufficiency. In: Gloviczki P, Yao JST, eds. Handbook of Venous Disorders. Guidelines of the American Venous Forum. London: Chapman \& Hall; 1996:3-26

47. Michel CC. Oxygen diffusion in oedematus tissue and through pericapillary cuffs. Phlebology 1990;5:223-230 
48. Coleridge Smith PD The microcirculation in venous hypertension. Vasc Med 1997;2:203-213

49. Nicolaides AN, Hussein MK, Szendro G, Christopoulos D, Vasdekis S, Clarke H. The relation of venous ulceration with ambulatory venous pressure measurements. J Vasc Surg 1993;17:414-419

50. Christopoulos D, Nicolaides AN, Cook A, Irvine A, Galloway JM, Wilkinson A. Pathogenesis of venous ulceration in relation to the calf muscle pump function. Surgery 1989;106:829-835

51. Darke SG, Penfold CAD. Venous ulceration and saphenous ligation. Eur J Vasc Surg $1992 ; 6: 4-9$

52. Burnand KG, Thomas ML, O'Donnell TF Jr, Browse NL. Relation between postphlebitic changes in the deep veins and results of surgical treatment of venous ulcers. Lancet 1976;1:936-938

53. Cikrit DF, Nichols WK, Silver D. Surgical management of refractory venous stasis ulceration. J Vasc Surg 1988;7:473-478

54. Masuda EM, Kistner RL. Long-term results of venous valve reconstruction: A four- to twenty-one-year follow-up. J Vasc Surg 1994;19:391-403

55. Kistner RL, Eklof B, Masuda EM. Deep venous valve reconstruction. Cardiovasc Surg 1995;3:129-140

56. Raju S, Neglen P, Doolittle J, Meydrech EF. Axillary vein transfer in trabeculated postthrombotic veins. J Vasc Surg 1999;29:1050-1064

57. Juhan CM, Alimi YS, Barthelemy PJ, Fabre DF, Riviere CS. Late results of iliofemoral venous thrombectomy. J Vasc Surg 1997;25:417-422 
Although the clinical history and physical examination are important first steps in the evaluation and management of venous disease, experience has shown these can be refined with utilization of vascular laboratory data. Noninvasive tests such as duplex evaluation for the presence or absence of deep venous thrombosis, assessment of valvular reflux, as well as air and photo plethysmography add a great deal to the specific diagnosis and selection of treatment options. It is important to identify sites of reflux and obstruction prior to surgical treatment of chronic venous insufficiency. ${ }^{1}$ To that end, knowledge of the patterns of chronic venous insufficiency encountered in patients with chronic venous insufficiency is clearly desirable. The review of etiology and anatomic distribution of venous disease in patients with venous ulcers by Drs. Labropoulos and Tassiopoulus is therefore important both from a research and clinical perspective. One particular strong point of this paper is that it incorporates a standardized classification of venous disease, allowing for more meaningful comparison of studies designed to evaluate results of specific interventions and thus strengthening and clarifying the data underlying their potential clinical application.

To describe newer data on the etiology and anatomic distribution of venous disease in patients with venous ulcers, Labropoulos and Tassiopoulos reviewed several articles addressing venous disease by etiology and anatomic distribution according to the CEAP classification system. ${ }^{2}$ This system, which categorizes venous disease by clinical (C), etiologic (E), anatomic (A), and pathophysiologic $(\mathrm{P})$ features, is a major step forward to accurate and reproducible classification of chronic venous insufficiency. The review focuses primarily on two studies, one by Kistner ${ }^{3}$ and the other by Labropoulos, ${ }^{4}$ which both describe chronic venous insufficiency with the new CEAP system. The article is quite specific and contains many interesting details concerning the etiology and distribution of abnormalities in chronic venous insufficiency. It is somewhat surprising to note isolated deep venous insufficiency was seen in only $6 \%$ of limbs with venous ulcers, ${ }^{5}$ and that isolated superficial incompetence in some studies was seen in up to $54 \%$ of limbs with venous ulcers. Labropoulos and Tassiopoulos therefore suggest that the distribution of venous disease according to the CEAP classification system indicates that a significant portion of patients with venous ulceration could and should be treated with surgical intervention on the superficial venous system. The authors also note only $30-40 \%$ of patients with chronic venous insufficiency

W.K.W., Resident; G.L.M., Professor of Vascular Surgery, Department of Surgery, Division of Vascular Surgery, Oregon Health Sciences University, Portland, OR.

Copyright (C) 2000 by Thieme Medical Publishers, Inc., 333 Seventh Avenue, New York, NY 10001, USA. Tel. +l(212) 584-4662. 0894-8046,p; 2000,12,2,127,128,ftx,en;pvs00073 
have a prior history of deep venous thrombosis, ${ }^{5}$ and therefore contend congenital or acquired venous wall weakness may be more prevalent an etiology of chronic venous insufficiency than has been previously recognized.

Overall, Labropoulos' and Tassiopoulos' review is well organized and of appropriate breadth. The information presented provides important data for the clinician to consider when evaluating a patient with venous ulcer disease and when considering various treatment options. Perhaps as more outcome data are obtained for patients evaluated with newer Duplex technology and classified under the CEAP system, indications for and outcomes of operative intervention in chronic venous insufficiency may be clarified by real data.

\section{REFERENCES}

1. Nehler MR, Moneta GL, Porter JM. Nonoperative management of chronic venous insufficiency of the lower extremities. In: Gloviczki P, Yao JS, ed. Handbook of Venous Disorders. London: Chapman and Hall Medical; 1996:416-433

2. Porter JM, Moneta GL, and An International Consensus Committee on Chronic Venous Disease. Reporting standards in venous disease: An update. J Vasc Surg 1988;8:172-181

3. Kistner RL, Eklof B, Masuda EM. Diagnosis of chronic venous disease of the lower extremities: The "CEAP" classification. Mayo Clin Proc 1996;71:338-345

4. Labropoulos N. CEAP in clinical practice. J Vasc Surg 1997;31:224-225

5. O'Donnell TF. Clinical Diagnosis and Classification of Chronic Venous Insufficiency. In: Rutherford R, ed. Vascular Surgery, 3rd ed. Philadelphia: WB Saunders; 1989:15041512 

Apostolos K. Tassiopoulos, M.D.

Patients with venous ulceration have more venous sites involved compared to the rest of chronic venous insufficiency classes. Our paper and the commentary emphasize the use of duplex scanning to delineate the distribution and extent of venous reflux and obstruction. The addition of plethysmographic testing aids the overall hemodynamic evaluation and provides objective evidence for lower limb function improvement after an intervention. The use of a standardized classification allows meaningful comparisons among different studies. However, today there are very few studies that have used the CEAP system, and therefore our knowledge on venous ulceration is limited. From the current studies it appears that the majority of limbs with venous ulceration have reflux only. Obstruction or deep venous reflux only is uncommon. These findings suggest that most limbs are amenable to surgical treatment. Prospective studies in a large number of patients will increase our understanding on pathophysiology of venous ulceration and on the effects of different interventions on healing, recurrence, and ulcer-free length of time. 
